\title{
Analysis of the Current Status and Characteristics of the Hearing Impaired Using Data from the Actual Survey for the Disabled
}

\author{
Soo Jin Cho ${ }^{1,2}$, Mi Sook Lee ${ }^{3}$, Yu Ri Lee ${ }^{4}$ \\ ${ }^{1}$ Department of Speech-Language Pathology, Nambu University, Gwangju, Korea \\ ${ }^{2}$ Department of Social Welfare, Graduate School, Nambu University, Gwangju, Korea \\ ${ }^{3}$ Faculty of Social Welfare and Rehabilitation, Kaya University, Gimhae, Korea \\ ${ }^{4}$ Department of Social Welfare, Nambu University, Gwangju, Korea
}

\author{
Received: October 27, 2021 \\ Revised: January 12, 2022 \\ Accepted: January 13, 2022 \\ Correspondence: \\ Yu Ri Lee, PhD \\ Department of Social Welfare, \\ Nambu University, 1 Nambudae- \\ gil, Gwangsan-gu, Gwangju 62271 \\ Korea \\ Tel: $+82-62-970-0135$ \\ Fax: +82-62-970-0049 \\ E-mail: yrlee@nambu.ac.kr
}

\begin{abstract}
Purpose: This study intends to analyze the current status and characteristics of the hearing impaired by analyzing 'actual survey data for the disabled' from 2005 to recent, and to use them as basic data for establishing rehabilitation and welfare service policies for the hearing impaired. Methods: Among the items related to hearing impairment in the survey data, longitudinal, and meaningful areas such as general characteristics, hearing aid and communication, education and welfare services of the hearing impaired were mainly analyzed. Results: The prevalence of hearing impairment was $0.65 \%$ to $0.66 \%$ and the age distribution of the hearing impaired increased rapidly after the age of 50 , and the proportion of over 65 years old increased by about $17.9 \%$ from $55.3 \%$ in 2008 to $73.2 \%$ in 2017 . The rate of acquired factors (5.2\% as of 2017) was higher than that of congenital factors as the cause of hearing impairment. The rate of people with hearing impairment who did not attend school increased as they went up from elementary school to high school, and the rate was the highest among the major areas of disability. Among the welfare needs of the hearing impaired, income security $(40.4 \%$ as of 2017) was the highest. Conclusion: If research that reflects the various characteristics of hearing impairment is expanded in addition to periodic actual surveys for the disabled in the future, the current results is expected that it can be used as basic data for mid- to long-term welfare policies for the hearing impaired.
\end{abstract}

Key Words: Hearing impairment, Hearing impaired, Actual survey for the disabled, Rehabilitation welfare services.

\section{INTRODUCTION}

코비드-19 (COVID-19)의 지역사회 확산과 팬데믹(pandemic) 으로의 확대는 그 동안 전 세계가 겪어보지 못한 새로운 위험 현상을 초래하였고, 감염병에 의한 사회적 안전망의 시험무대 가 되기도 하였다. 또한 전 국민이 방역에 최대한 협조하였음 에도 정부는 사회의 다양한 사각지대에 제대로 대응하지 못함 으로써 사회복지 전반에 걸쳐 많은 변화를 초래하였다. 이처럼 COVID-19는 모든 사람들의 일상생활에 제약을 가져왔는데, 특 히 만성 기저질환의 발생 가능성이 높은 장애인 집단의 경우 기

(c) This is an Open Access article distributed under the terms of the Creative Commons Attribution Non-Commercial License (https://creativecommons.org/ licenses/by-nc/4.0) which permits unrestricted non-commercial use, distribution, and reproduction in any medium, provided the original work is properly cited.
존 COVID-19의 감염으로 인한 위험뿐만 아니라 돌봄, 사회참 여, 자립생활 등 여러 가지 측면에서 다양한 어려움을 겪고 있다. 이에 세계보건기구(World Health Organization)에서는 국가 별로 장애인 집단의 고질적인 보건구조 문제와 사회적 불평 등으 로 인한 위험에 대비할 수 있는 대응책 마련을 권고하고 있다.

이와 같이 국가적 위기 상황에서 취약 계층인 장애인에 대한 신속한 대응책 마련이나 장기적인 국가 정책을 수립하고 정책의 대상이 되는 장애인의 욕구를 정확히 파악하기 위해서 선행해 야 할 것이 실태조사이다. 장애인실태조사의 일차적인 목적은 장 애인구와 장애인의 생활실태를 파악함으로써 장.단기 장애인복 지정책 수립 및 시행을 위한 기초 자료를 파악하고, 장애인의 사 회·인구학적 및 경제적 특성, 장애유형별 장애특성, 복지욕구, 복 지서비스 수혜 실태 등에 관한 구체적인 통계자료를 얻고자 하는 
데 있다.

우리나라의 경우 장애인복지법 제31조 및 장애인복지시행령 제18조에 근거하여 시행되는 『장애인실태조사」를 1980년부터 5년 주기로 실시하고 있으며, 2007년부터는 장애인복지법 개정 으로 3년마다 장애인실태조사를 실시하도록 규정이 바뀌었다. 최근 2020년에 실시된 장애인실태조사에 의하면, COVID-19 의 장기화로 인한 영향은 사회 전반적인 영역뿐만 아니라 장애 인의 실생활에도 큰 영향을 미치는 것으로 나타났다. 구체적으 로 장애인들은 '외출', '정서적 안정', '경제활동', '의료이용' 등의 항목에서 가장 많은 어려움을 겪는 것으로 조사되었으며, 이러 한 결과를 바탕으로 COVID-19 사태 이후의 다양한 정책을 마 련할 것이라고 보고하였다(Ministry of Health and Welfare, 2021a).

2020년 말 기준 국내 등록장애인 중 지체장애인(45.8\%)에 이 어 두 번째로 많은 청각장애인(15\%)은 청각을 통한 정보 습득과 의사소통의 어려움 때문에 수많은 위기 상황에서 의료와 보건 영역뿐만 아니라, 일상생활 전 영역에 걸쳐 심각한 영향을 받고 있다. 특히 COVID-19의 대유행으로 마스크 쓰기가 생활화됨 에 따라 특히 수어나 몸짓, 표정, 입술의 움직임 등 독화를 통해 의사소통을 해야 하는 청각장애인은 의사소통의 어려움, 정보의 소외 및 가짜 뉴스나 과장된 정보 등으로 인해 불안감이 더 가중 될 수밖에 없다. 따라서 청각장애인이 COVID-19와 같은 위기 상황 속에서 비장애인과 동일하게 인간으로서의 권리를 가지고 의미 있는 생활을 영위할 수 있는 사회적 지원체계를 구축하기
위해서 청각장애인 중심의 실태조사 및 관련 연구가 필요하다.

청각장애인 중심의 실태조사 중 『청각장애인 복지서비 스 이용실태 및 욕구조사』는 기존 장애인실태조사가 획일적 이고 장애유형별 특성을 잘 반영하지 못한다는 한계점을 보 완하기 위해 실시되었다. 특히 설문조사 시 수화통역사의 도 움을 제공함으로써 청각장애인의 의사소통 문제를 최소화 하는 한편, 설문문항을 쉽게 풀이하는 등 청각장애인의 특 성을 고려하여 실시된 최초의 전국 조사로써 그 의의가 있 다(Korean Disabled People's Development Institute, 2019). 그 결과에 따르면 청각장애인을 위한 개별화된 재활 정 보제공 및 맞춤형 서비스 지원에 대한 욕구가 높았으며, 의사 소통을 보완해 줄 수 있는 보청기나 인공와우 시술의 경우 교 체 및 수리비용의 자부담 비율이 지원금보다 더 높게 나타났 다. 이로 인해 청각보조기기 구입의 어려움이 가중되어 의사 소통문제와 일상생활 제한에 영향을 줄 수 있으므로 청각보 조기기 구입 및 수리 지원금의 확대와 지역사회 내 기관들의 협력을 통한 통합적인 재활서비스 지원이 필요함을 제언하였 다. 그 밖에 다양한 연구 결과 및 의견수렴을 토대로 보건복지 부는 보청기 가격에 대한 부담을 최소화하기 위하여 2015년 말부터 보청기 지원금을 기존 34 만 원에서 최대 131 만 원으로 확대한 바 있다. 청각장애실태조사와 관련된 연구 중 1995년부 터 2005년까지 청각장애를 중심으로 한국의 장애인실태조사 내용을 분석한 Koo et al.(2006)의 연구에서는 개별 의료중심 모델에서 사회 환경중심 모델로 변화된 장애 개념 인식과 개별

Table 1. The size of the actual survey for the disabled

\begin{tabular}{lcccccc}
\hline & Surveyed areas & Target household & $\begin{array}{c}\text { Completed } \\
\text { households }\end{array}$ & $\begin{array}{c}\text { Survey completion } \\
\text { rate (\%) }\end{array}$ & Surveyed people & Surveyed disabled $^{\ddagger}$ \\
\hline 2005 & 200 & 45,285 & 40,556 & 89.6 & $119,306(2.94)$ & 5,466 \\
$2008^{\dagger}$ & - & - & - & - & - & 7,000 \\
2011 & 200 & 47,458 & 38,231 & 80.6 & $105,496(2.76)$ & 6,010 \\
2014 & 200 & 48,344 & 38,560 & 79.8 & $104,703(2.72)$ & 6,824 \\
2017 & 200 & 44,161 & 36,200 & 81.9 & $91,405(2.53)$ & 6,549 \\
$2020^{\dagger}$ & - & - & - & - & - & 7,025 \\
\hline
\end{tabular}

${ }^{\dagger}$ In 2008 and 2020, the surveys were conducted with the registered disabled database as the population. ${ }^{*}$ The number of people surveyed per household

Table 2. The estimated number of people with disabilities nationwide

\begin{tabular}{lccccc}
\hline & Home disabled & Facility disabled & Total & Disability registration rate (\%) & Disability prevalence $^{\dagger}(\%)$ \\
\hline 2005 & $2,101,057$ & 47,629 & $2,148,686$ & 77.7 & 4.59 \\
2011 & $2,611,126$ & 72,351 & $2,683,477$ & 93.8 & 5.61 \\
2014 & $2,646,064$ & 80,846 & $2,726,910$ & 91.7 & 5.59 \\
2017 & $2,580,340$ & 88,071 & $2,668,411$ & 94.1 & 5.39 \\
\hline
\end{tabular}

Data for 2008 and 2020 were omitted because the surveys were conducted using the registered disabled database as a population. ${ }^{\dagger}$ Disability prevalence: the number of people with disabilities per 1,000 population 
화된 청능재활 프로그램 및 정책 개발을 강조하고 있다.

이에 본 연구의 목적은 Koo et al.(2006)의 후속 연구 개념으 로 2005년 이후부터 최근까지 시행된 장애인실태조사 자료를 분석하여 청각장애인의 현황을 일반적 특성, 청각보조기기, 의 사소통, 교육 및 복지서비스 등 다양한 영역으로 나누어 분석해 보고, 이를 통해서 청각장애인의 재활복지서비스 정책 수립을 위한 기초자료로 활용하고자 한다.

\section{MATERIALS AND METHODS}

\section{장애인실태조사 규모 및 현황}

일반적으로 장애인실태조사는 인구주택총조사의 조사구를 표본추출 모집단으로 하고, 200개 지역과 200여 가구 이상을 층화추출하여 조사원의 가구방문 면접조사를 통해서 실시된 다. 다만, 2008년 조사의 경우 가구표본조사가 아닌 보건복지부 의 등록장애인 데이터베이스(database, $\mathrm{DB}$ )를 모집단으로 성 별, 연령, 장애유형, 장애등급, 지역 등을 고려한 표본을 추출하 여 등록장애인만을 대상으로 심층 면접조사를 통해 진행되었 다. 이런 배경에는 국가 주요 통계 작성 및 활용실태와 관련하여 장애인실태조사 대상 선정 시 비장애인을 조사 대상에 포함시켜 예산 낭비를 초래한다는 2007년 감사원의 감사 결과에 따른 것 이었다. 또한 2020년에 실시된 장애인실태조사에서도 조사환경
악화(COVID-19 감염병 확산 등)를 고려하여 등록장애인 DB를 모집단으로 진행하여 2017년 이전의 조사 방식과 차이가 있다. 이러한 방법은 그 결과가 과거의 가구접근법에 의한 장애인의 특 성과 차이가 날 수 있으며 시계열 유지에도 어려움이 있지만, 등 록장애인 $\mathrm{DB}$ 를 모집단으로 한 관계로 법정 장애인의 특성을 보 다 정확히 파악할 수 있다는 장점도 있다(Korea Institute for Health and Social Affairs, 2009).

Table 1은 2005년 이후부터 2020년까지 진행된 장애인실태 조사 규모에 대한 현황을 비교한 것으로, 등록장애인 $\mathrm{DB}$ 를 기준 으로 조사한 2008년과 2020년을 제외하고 조사 완료한 평균 가 구원수는 2005년 2.94명에서 2011년 2.76명, 2014년 2.72명, 2017년 2.53명으로 지속적으로 감소하고 있다. 조사 장애인수 는 2005년 5,466명에서 2020년 7,025명으로 1,559 명 정도 증 가한 것으로 나타났다.

\section{자료 분석}

장애인실태조사는 장애인(가구) 특성(장애인구 및 출현율 등), 15 개 장애유형별 특성 및 장애 공통사항(보건의료 및 건강, 일상 생활 지원, 장애인보조기구, 교육, 취업 및 직업생활 등)에 대한 내용으로 구성되어 있다. 본 연구에서는 전체 장애인의 현황(전 국 장애인 추정 수, 장애 등록률, 장애 출현율)을 분석하여 그 경 향을 파악한 후, 청각장애인의 현황과 특성을 살펴보았다. 구체

Table 3. The prevalence of hearing impairment (Including multiple disabilities)

\begin{tabular}{|c|c|c|c|c|c|c|c|c|}
\hline & \multicolumn{2}{|r|}{2005} & \multicolumn{2}{|r|}{2011} & \multicolumn{2}{|r|}{2014} & \multicolumn{2}{|r|}{2017} \\
\hline & Disabled $^{\dagger}$ & Prevalence (\%) & Disabled $^{\dagger}$ & Prevalence (\%) & Disabled $^{\dagger}$ & Prevalence (\%) & Disabled $^{\dagger}$ & Prevalence (\%) \\
\hline Physical disability & 1,048 & 2.24 & 1,385 & 2.90 & 1,387 & 2.85 & 1,310 & 2.65 \\
\hline Brain lesions & 301 & 0.64 & 347 & 0.73 & 321 & 0.66 & 320 & 0.65 \\
\hline Visual impairment & 280 & 0.60 & 288 & 0.60 & 312 & 0.64 & 292 & 0.59 \\
\hline Hearing impairment & 302 & 0.65 & 315 & 0.66 & 318 & 0.65 & 323 & 0.65 \\
\hline Language disorder & 237 & 0.51 & 104 & 0.22 & 123 & 0.25 & 97 & 0.20 \\
\hline Intellectual disability & 164 & 0.35 & 203 & 0.43 & 239 & 0.49 & 244 & 0.49 \\
\hline $\begin{array}{l}\text { Autism spectrum } \\
\text { disorders }\end{array}$ & 35 & 0.07 & 22 & 0.05 & 22 & 0.05 & 25 & 0.05 \\
\hline Mental disorder & 105 & 0.22 & 121 & 0.25 & 124 & 0.25 & 120 & 0.24 \\
\hline Renal disorder & 41 & 0.09 & 64 & 0.13 & 75 & 0.16 & 89 & 0.18 \\
\hline Cardiac disorder & 59 & 0.13 & 22 & 0.05 & 9 & 0.02 & 7 & 0.01 \\
\hline Respiratory disorder & 37 & 0.08 & 20 & 0.04 & 16 & 0.03 & 14 & 0.03 \\
\hline $\begin{array}{l}\text { Hepatobiliatry } \\
\text { disorder }\end{array}$ & 16 & 0.03 & 10 & 0.02 & 12 & 0.03 & 12 & 0.02 \\
\hline Facial disability & 5 & 0.01 & 3 & 0.01 & 3 & 0.01 & 4 & 0.01 \\
\hline $\begin{array}{l}\text { Intestinal fistular/ } \\
\text { urinary fistular }\end{array}$ & 17 & 0.04 & 20 & 0.04 & 18 & 0.04 & 19 & 0.04 \\
\hline Epilepsy disability & 27 & 0.06 & 20 & 0.04 & 22 & 0.05 & 23 & 0.05 \\
\hline
\end{tabular}

${ }^{\dagger}$ Disabled: estimated number of disabled people (unit: thousand people) 
적으로는 청각장애 관련 항목 중 종단적 비교가 가능하고 의미 있는 내용을 청각장애인의 일반적 특성(출현율, 연령분포, 발생 원인 및 시기, 장애 정도), 청각보조기기 및 의사소통(보청기 사 용률 및 청각보조기기 구입경로, 주 의사소통 방법), 교육 및 복 지서비스(학교에 다니지 않는 비율, 장애인 등록 후 받은 혜택 정 도, 사회나 국가에 대한 복지 욕구, 생활만족도, 주관적 경제 계층
인식) 등 다양한 영역으로 나누어 그 현황과 특성을 살펴보았다.

\section{RESULTS}

\section{전체 장애인의 현황 분석}

전국의 장애인 추정 수를 살펴보면, 2005년 2,148,686명에

Table 4. Age distribution rates of total disabled and the hearing impaired by year

\begin{tabular}{|c|c|c|c|c|c|c|c|c|c|c|}
\hline \multirow[b]{2}{*}{ Age (yr) } & \multicolumn{2}{|c|}{2008} & \multicolumn{2}{|c|}{2011} & \multicolumn{2}{|c|}{2014} & \multicolumn{2}{|c|}{2017} & \multicolumn{2}{|c|}{2020} \\
\hline & $\begin{array}{c}\text { Disabled }^{\dagger} \\
(\%)\end{array}$ & $\begin{array}{c}\text { Hearing } \\
(\%)\end{array}$ & $\begin{array}{c}\text { Disabled }^{\dagger} \\
(\%)\end{array}$ & $\begin{array}{l}\text { Hearing } \\
(\%)\end{array}$ & $\begin{array}{c}\text { Disabled }^{\dagger} \\
(\%)\end{array}$ & $\begin{array}{c}\text { Hearing } \\
(\%)\end{array}$ & $\begin{array}{c}\text { Disabled }^{\dagger} \\
(\%)\end{array}$ & $\begin{array}{c}\text { Hearing } \\
(\%)\end{array}$ & $\begin{array}{c}\text { Disabled }^{\dagger} \\
(\%)\end{array}$ & $\begin{array}{l}\text { Hearing } \\
(\%)\end{array}$ \\
\hline $0 \sim 17$ & 3.9 & 2.1 & 3.5 & 1.2 & 2.7 & 1.6 & 3.3 & 1.6 & 3.0 & - \\
\hline $18 \sim 29$ & 4.0 & 1.7 & 4.2 & 3.1 & 4.1 & 2.2 & 4.6 & 2.6 & 4.2 & - \\
\hline $30 \sim 39$ & 7.4 & 4.0 & 7.2 & 3.9 & 6.7 & 4.0 & 4.8 & 2.4 & 4.8 & - \\
\hline $40 \sim 49$ & 16.7 & 9.6 & 14.2 & 9.2 & 12.5 & 7.5 & 10.4 & 4.5 & 9.5 & - \\
\hline $50 \sim 64$ & 32.0 & 27.3 & 32.1 & 25.5 & 30.7 & 21.8 & 30.3 & 15.7 & 28.7 & - \\
\hline Over 65 & 36.1 & 55.3 & 38.8 & 57.2 & 43.3 & 63.0 & 46.6 & 73.2 & 49.9 & - \\
\hline Total & 100.0 & 100.0 & 100.0 & 100.0 & 100.0 & 100.0 & 100.0 & 100.0 & 100.0 & - \\
\hline
\end{tabular}

${ }^{\dagger}$ Disabled: total disabled people. ${ }^{*}$ Hearing: specific data on individual disability areas, including hearing impairment, from the 2020 survey have not yet been released

Table 5. Causes of hearing impairment

\begin{tabular}{|c|c|c|c|c|c|c|c|c|c|c|c|c|}
\hline & \multicolumn{3}{|c|}{2008} & \multicolumn{3}{|c|}{2011} & \multicolumn{3}{|c|}{2014} & \multicolumn{3}{|c|}{2017} \\
\hline & $\mathrm{M}(\%)$ & $\mathrm{F}(\%)$ & Total (\%) & M (\%) & $\mathrm{F}(\%)$ & Total (\%) & M (\%) & $\mathrm{F}(\%)$ & Total (\%) & M (\%) & $\mathrm{F}(\%)$ & Total (\%) \\
\hline Congenital & 5.8 & 8.8 & 7.1 & 3.0 & 3.8 & 3.3 & 7.9 & 7.0 & 7.5 & 2.8 & 6.6 & 4.5 \\
\hline At birth & 0.1 & 0.0 & 0.0 & 0.5 & 0.9 & 0.7 & 1.3 & 1.2 & 1.2 & 0.6 & 0.5 & 0.6 \\
\hline \multicolumn{13}{|l|}{ Acquired } \\
\hline Disease & 73.9 & 73.7 & 73.8 & 72.0 & 80.9 & 75.6 & 68.5 & 77.9 & 72.8 & 78.9 & 82.3 & 80.4 \\
\hline Accident & 14.8 & 11.7 & 13.4 & 19.0 & 11.0 & 15.7 & 14.0 & 8.4 & 11.4 & 14.8 & 8.4 & 12.0 \\
\hline Unknown & 5.5 & 5.7 & 5.6 & 5.5 & 3.4 & 4.7 & 8.3 & 5.5 & 7.0 & 2.9 & 2.1 & 2.6 \\
\hline
\end{tabular}

M: male, F: female

Table 6. The time of onset in acquired hearing impairment according to age (after 1 year old)

\begin{tabular}{|c|c|c|c|c|c|c|c|c|c|c|c|c|}
\hline \multirow{2}{*}{ Age (yr) } & \multicolumn{3}{|c|}{2008} & \multicolumn{3}{|c|}{2011} & \multicolumn{3}{|c|}{2014} & \multicolumn{3}{|c|}{2017} \\
\hline & M (\%) & $\mathrm{F}(\%)$ & Total (\%) & M (\%) & $\mathrm{F}(\%)$ & Total (\%) & $\mathrm{M}(\%)$ & $\mathrm{F}(\%)$ & Total (\%) & M (\%) & F (\%) & Total (\%) \\
\hline $1 \sim 4$ & 6.2 & 5.1 & 5.7 & 7.2 & 9.0 & 7.9 & 9.7 & 8.9 & 9.3 & 6.2 & 10.9 & 8.2 \\
\hline $5 \sim 9$ & 2.5 & 2.1 & 2.3 & 6.2 & 6.3 & 6.2 & 8.3 & 10.9 & 9.5 & 7.6 & 6.4 & 7.1 \\
\hline $10 \sim 19$ & 6.9 & 5.4 & 6.2 & 8.5 & 4.4 & 6.8 & 7.1 & 7.2 & 7.1 & 7.3 & 4.9 & 6.3 \\
\hline $20 \sim 29$ & 4.5 & 3.7 & 4.2 & 11.8 & 4.6 & 8.8 & 8.6 & 5.0 & 6.9 & 9.1 & 4.0 & 6.9 \\
\hline $30 \sim 39$ & 6.0 & 7.6 & 6.7 & 5.6 & 7.4 & 6.4 & 6.1 & 7.2 & 6.6 & 3.4 & 2.8 & 3.2 \\
\hline $40 \sim 49$ & 14.2 & 9.1 & 12.0 & 9.6 & 12.1 & 10.6 & 6.8 & 8.0 & 7.3 & 6.7 & 8.5 & 7.5 \\
\hline $50 \sim 59$ & 19.6 & 21.2 & 20.3 & 14.0 & 14.1 & 14.0 & 15.9 & 10.4 & 13.3 & 19.1 & 9.9 & 15.1 \\
\hline $60 \sim 69$ & 24.2 & 20.6 & 22.6 & 20.5 & 16.0 & 18.6 & 21.1 & 21.2 & 21.1 & 20.2 & 22.4 & 21.2 \\
\hline Over 70 & 15.8 & 25.1 & 19.9 & 16.7 & 26.2 & 20.6 & 16.5 & 21.3 & 18.7 & 20.3 & 30.1 & 24.6 \\
\hline
\end{tabular}

M: male, F: female 
서 2014년 2,726,910명으로 증가하였으나 2017년 2,668,411명 으로 약간 감소하였으며, 지역사회에 거주하고 있는 재가 장애 인도 비슷한 양상을 보이고 있다. 하지만 시설에 거주하고 있

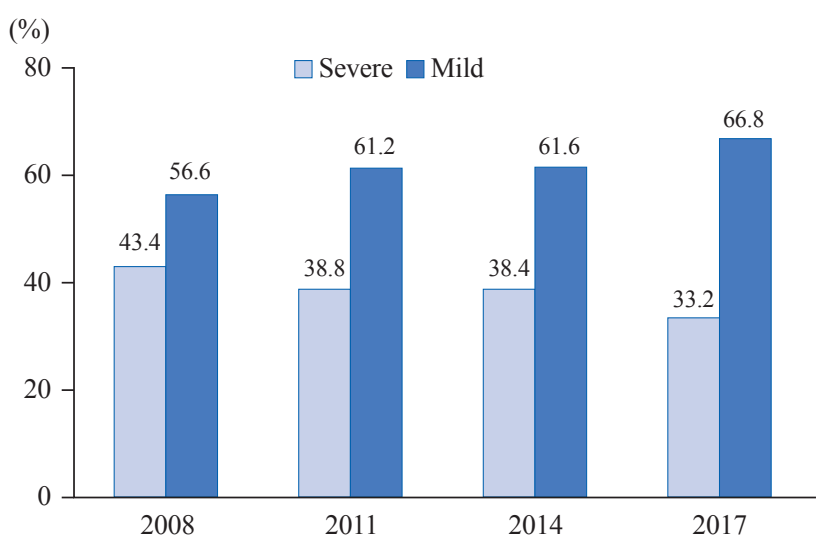

Figure 1. The degree of disability of the hearing impaired.

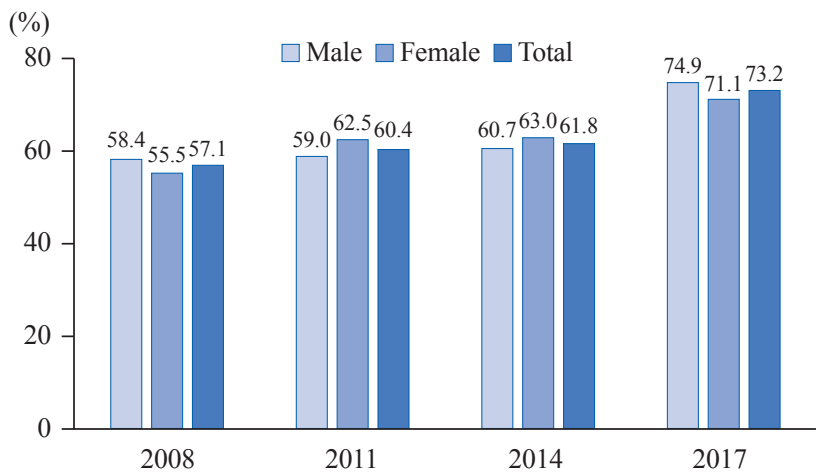

Figure 2. The rate of hearing aid use of the hearing impaired.
는 장애인의 경우 지속적으로 증가하고 있는 것으로 나타났다 (Table 2). 장애 등록률은 2005년도 77.7\%에서 2011년 93.8\% 로 $16.1 \%$ 증가하였고, 이후부터는 계속해서 $90 \%$ 이상을 상회하 고 있다. 장애 출현율은 2005년 4.59\%에서 2011년 5.61\%로 상 승하였으나, 2014년 5.59\%와 2017년 5.39\%로 지속적인 감소 추세를 보이고 있다.

\section{청각장애인의 현황 분석}

\section{일반적 특성}

개별 장애 영역 중 청각장애의 출현율(중복장애 포함)은 Table 3 에서 나타난 바와 같이 지체장애나 뇌병변장애와 함께 높게 나 타났고, 안면장애와 심장장애가 가장 낮은 출현율을 보였다 (Table 3). 연도별 비교에서 2005년 302천 명(0.65\%) 2011년 315천 명(0.66\%), 2014년 318천 명(0.65\%), 2017년 323천 명 (0.65\%)으로 청각장애인 수는 매년 약간씩 증가하였으나, 장애 출현율은 평균 $0.65 \sim 0.66 \%$ 로 조사되어 큰 변화가 없는 것으로 나타났다.

청각장애인의 연령 분포는 50 대 이후에 급격히 증가하였 고, 65세 이상이 차지하는 비율이 2008년 55.3\%에서 2017년 $73.2 \%$ 로 약 $17.9 \%$ 의 증가율을 보여 다른 장애유형에 비해 증가 폭이 훨씬 크게 나타나 장애인구의 고령화 현상이 두드러짐을 알 수 있었다(Table 4).

청각장애인뿐만 아니라 전체 재가 장애인의 연령분포에서도 이러한 고령화 현상이 나타났는데, 2008 2020년 조사에서 만 65세 이상의 비율이 가장 높았으며, 2020 년의 경우 장애인의 약 $50 \%$ 정도가 만 65 세 이상의 노인 인구로 나타났다(Table 4).

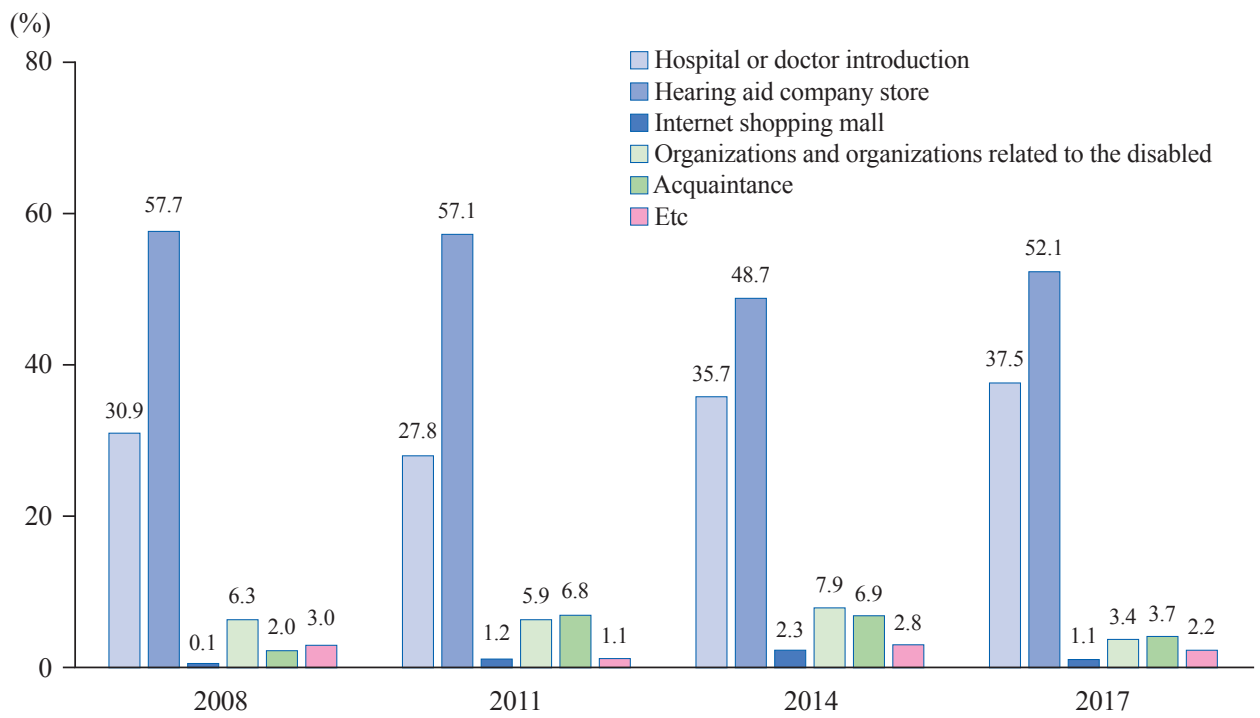

Figure 3. The purchase route of hearing assistive device currently in use. 
연도별 변화 추이를 살펴보면, 만 65세 이상이 차지하는 비율 은 2008년 36.1\%에서 지속적으로 증가하기 시작하여 2020년 49.9\%로 2008년 대비 $13.8 \%$ 증가를 나타내었다.

청각장애 발생의 주된 원인 중 후천적 원인의 비율은 2008년 $87.2 \%$ 에서 2017년 92.4\%로 5.2\% 증가하였으며, 선천적 원인에 비해 높게 나타났다(Table 5). 특히 2017년 기준 후천적 원인은 질환에 의한 경우가 $80.4 \%$, 사고가 $12.0 \%$ 로 질환에 의한 후천 적 청각장애 발생 비율이 더 높았다. 성별에 따른 후천적 원인을 살펴보면, 질환인 경우는 여자가, 사고인 경우는 남자가 그 비율 이 더 높게 나타났다.

청각장애의 발생 시기는 돌 이후가 평균 $90 \%$ 이상을 차지하 였고, 다음이 출생 전 또는 출생 시 그리고 돌 이전에 발생하는 것으로 나타났다. 돌 이후에 청각장애가 발생하였다고 응답한 경우를 연령대별로 구분해서 살펴본 결과, 연령이 높아질수록 발 생 비율이 높아지는 경향을 보였다(Table 6). 연도별 비교에서는 2014년도를 제외하고 만 70세 이상의 비율이 점차 증가하는 것 을 알 수 있다. 성별로 후천적 장애에 대한 발생 시기를 비교하였 을 때, 연령이 증가함에 따라 장애 발생이 증가 추세를 보이는 것 은 유사하지만, 남자는 50대에 증가폭이 큰 반면에 여자는 60대 이상에서 급격한 증가세를 나타내고 있다.

등록 청각장애인의 장애등급을 변경된 장애정도에 따라 분 석해 본 결과, 종전의 1 3급인 '장애의 정도가 심한 장애인(중

Table 7. The satisfaction with the use of assistive devices of the hearing impaired

\begin{tabular}{lrccc}
\hline & 2008 & 2011 & 2014 & 2017 \\
\hline Very satisfied (\%) & 16.7 & 11.8 & 11.5 & 14.8 \\
Slighty satisfied (\%) & 35.2 & 42.3 & 48.9 & 54.6 \\
Neutral (\%) & 17.9 & - & - & - \\
Slighty unsatisfied (\%) & 24.6 & 28.1 & 26.5 & 21.8 \\
Very dissatisfied (\%) & 5.5 & 17.8 & 13.0 & 8.7 \\
\hline
\end{tabular}

증)'의 경우 2008년 43.4\%에서 2017년 33.2\%로 감소하는 반면 에, 4 6급인 '장애의 정도가 심하지 않은 장애인(경증)'의 경우 2008년 56.6\%에서 2017년 66.8\%로 점차 증가하는 경향을 보 였다(Figure 1).

\section{청각보조기기와 의사소통 방법}

청각장애인의 주된 보조기기인 보청기를 사용하고 있는 청각 장애인은 2008년 57.1\%에서 2017년 73.2\%로 10년 동안 16.1\% 증가하였다(Figure 2). 이와 같은 보청기 사용 청각장애인의 증 가는 2015년 보청기 급여 기준금액이 34만 원에서 131만 원으 로 인상된 보장구 급여제도의 변화와 관련 있을 것으로 볼 수 있 다. 연도별 보청기 사용에 대한 성별 차이는 뚜렷한 특징을 나타 내지 않았다.

현재 사용 중인 청각보조기기의 구입경로는 '청각보조기기 업 체 매장에서 구입’했다고 응답한 비율이 가장 높았으며, ‘병원 또는 의사의 소개로 구입'했다고 응답한 비율이 그 뒤를 이었다 (Figure 3). '청각보조기기 업체 매장에서 구입'했다고 응답한 비율은 연도에 따라 차이가 있지만 2008년 57.7\%에서 2017년 $52.1 \%$ 로 약간 감소하는 경향을 보인 반면에, '병원 또는 의사의 소개로 구입했다'고 응답한 비율은 2008년 30.9\%에서 2017년 $37.5 \%$ 로 증가하는 양상을 나타내었다.

청각장애인의 보조기기 사용 만족도와 관련하여 '만족스럽다' 고 응답한 비율이 2008년 51.9\%에서 2017년 69.4\%로 17.5\% 상승하였다(Table 7).

청각장애인의 주된 의사소통 방법으로 '말'을 사용한다는 비 율이 평균 $80 \%$ 가 넘었고, 그 다음이 수화, 구화(입모양), 필담의 순으로 나타났다. 성별로는 '말'을 사용하는 비율이 남자에 비해 여자가 근소한 차이로 높았다(Table 8).

\section{교육 및 복지서비스 등}

청각장애인이 '학교에 다니지 않는 비율'을 학교 형태별로 분

Table 8. The main communication method of the hearing impaired

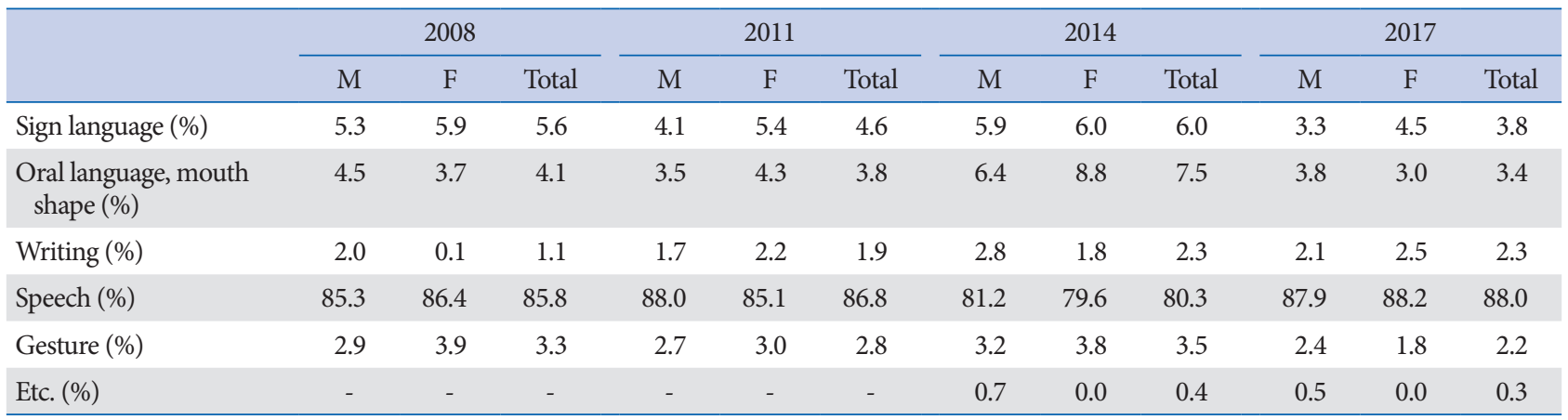

M: male, F: female 
석한 결과, 초등학교에서 고등학교로 올라갈수록 그 비율이 증 가하여 교육의 정도가 낮아짐을 알 수 있었다. 또한 다른 주요 장 애 영역과 비교한 결과, 청각장애인이 모든 조사연도에서 학교에 다니지 않는 비율이 가장 높게 나타났다(Table 9). 하지만 연도 가 경과함에 따라 학교에 다니지 않는 비율은 점차 감소하는 경 향을 보였다.

청각장애인으로 등록한 후 받은 혜택의 정도에 대해서는 '별 로 받지 못하고 있다'와 ‘전혀 받지 못하고 있다'고 응답한 비율이
2008년 58.5\%, 2011년 62.3\%, 2014년 64.4\%, 2017년 64.1\% 로 점차 증가하는 양상을 보였고(Figure 4), 전체 장애인의 평 균 수치인 2008년 54\%, 2011년 62.3\%, 2014년 64.2\%, 2017년 $64.2 \%$ 와 거의 비슷하거나 약간 높게 나타났다.

청각장애인의 복지 욕구를 알아보기 위하여 사회나 국가에 대한 요구사항을 분석한 결과, 1 순위로 응답한 항목이 '의료보 장, 주거보장, 고용보장, 소득보장, 장애인 인권보장 등이었다 (Figure 5). 연도별 변화 추이를 분석해 본 결과 2008년의 경우

Table 9. The rate of people with disability who did not attend school by major disability areas

\begin{tabular}{|c|c|c|c|c|c|c|c|}
\hline & $\begin{array}{c}\text { Physical } \\
\text { disability (\%) }\end{array}$ & $\begin{array}{c}\text { Brain lesions } \\
\text { (\%) }\end{array}$ & $\begin{array}{c}\text { Visual } \\
\text { impairment (\%) }\end{array}$ & $\begin{array}{c}\text { Hearing } \\
\text { impairment (\%) }\end{array}$ & $\begin{array}{l}\text { Language } \\
\text { disorder (\%) }\end{array}$ & $\begin{array}{c}\text { Mental } \\
\text { disorder (\%) }\end{array}$ & $\begin{array}{l}\text { Developmental disability, } \\
\text { autism disorder (\%) }\end{array}$ \\
\hline \multicolumn{8}{|l|}{2008} \\
\hline Elementary & 16.2 & 13.9 & 18.0 & 23.6 & 15.4 & 5.4 & 6.1 \\
\hline Middle & 50.1 & 49.0 & 49.4 & 59.5 & 42.1 & 21.5 & 10.5 \\
\hline High & 64.5 & 69.3 & 65.8 & 74.9 & 58.5 & 41.4 & 18.0 \\
\hline \multicolumn{8}{|l|}{2011} \\
\hline Elementary & 11.0 & 13.3 & 12.5 & 19.7 & 8.7 & 12.3 & 10.3 \\
\hline Middle & 43.4 & 49.7 & 42.0 & 56.7 & 33.3 & 32.1 & 0.0 \\
\hline High & 62.3 & 66.9 & 60.5 & 73.9 & 51.2 & 47.6 & 0.0 \\
\hline \multicolumn{8}{|l|}{2014} \\
\hline Elementary & 11.7 & 12.4 & 10.6 & 19.4 & 8.8 & 9.7 & 5.0 \\
\hline Middle & 41.9 & 41.7 & 38.8 & 52.7 & 42.0 & 29.5 & 1.8 \\
\hline High & 58.5 & 57.9 & 54.8 & 68.1 & 56.4 & 39.2 & 6.1 \\
\hline \multicolumn{8}{|l|}{2017} \\
\hline Elementary & 11.2 & 9.3 & 8.9 & 18.6 & 18.6 & 1.3 & 3.1 \\
\hline Middle & 40.0 & 34.3 & 35.7 & 51.0 & 34.5 & 16.4 & 0.7 \\
\hline High & 58.8 & 49.7 & 51.1 & 65.1 & 53.7 & 28.3 & 0.7 \\
\hline
\end{tabular}

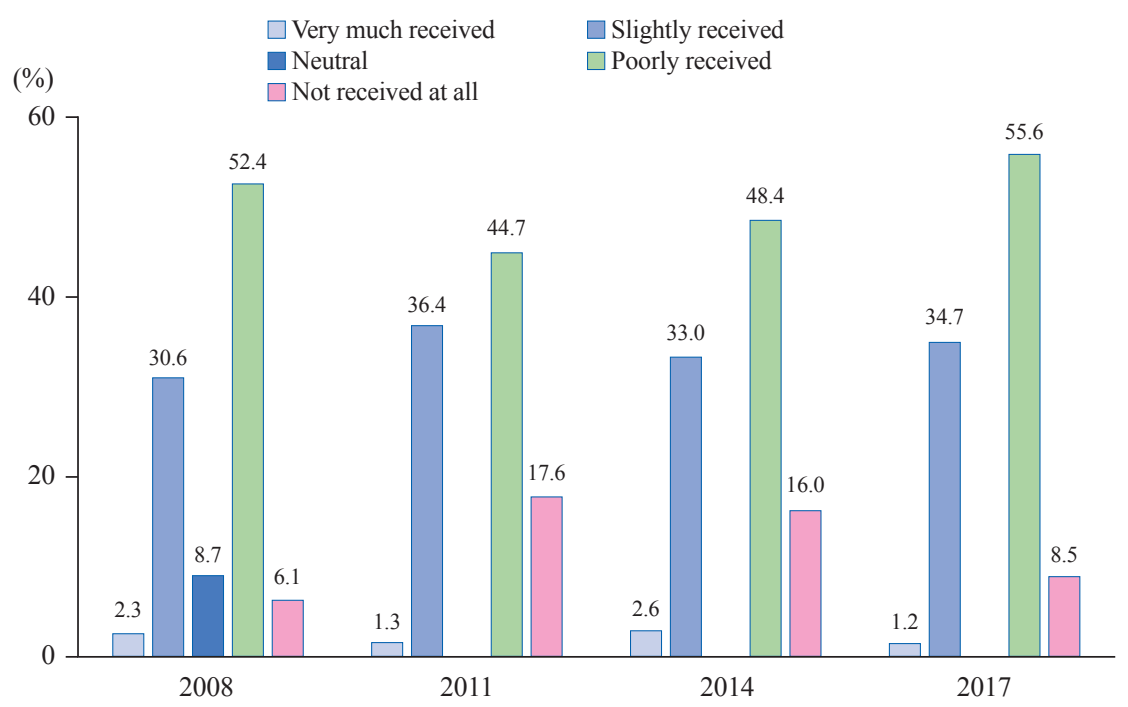

Figure 4. The degree of benefits received after registering with the hearing impaired. 
'의료보장(33.8\%)'이 가장 많았고 다음이 '소득보장(21.7\%)'이었 으며, 2011년부터는 이 항목의 순서가 바뀌어서 2017년까지 가 장 요구사항이 많은 항목이 '소득보장'으로 나타났으며 그 비율 도 점차 증가하였다. 그 외에 주거보장, 고용보장 및 장애인 인권 보장에 대한 요구는 점차 감소하는 것으로 나타났다.

청각장애인의 생활만족도를 2008년도에는 5점 척도로, 2011년 부터는 4점 척도로 조사한 결과 '현재 삶에 만족한다'는 긍정적

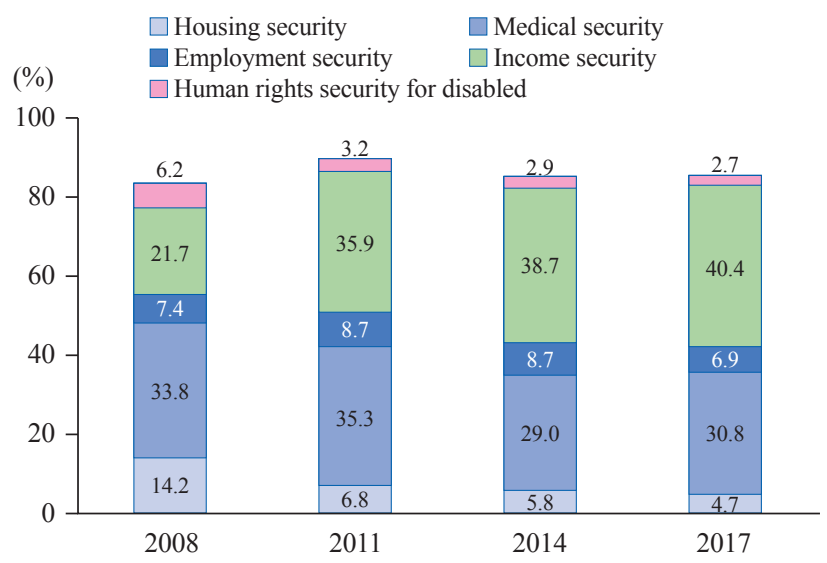

Figure 5. The main requirements of the hearing impaired to society and country (1st place).

Table 10. The life satisfaction of the hearing impaired

\begin{tabular}{lrrrr}
\hline & 2008 & 2011 & 2014 & 2017 \\
\hline Life satisfaction & & & & \\
Very satisfied (\%) & 3.8 & 9.0 & 6.8 & 4.0 \\
Slighty satisfied (\%) & 22.6 & 50.5 & 57.0 & 62.1 \\
Neutral (\%) & 49.0 & - & - & - \\
Slighty unsatisfied (\%) & 19.0 & 35.5 & 31.9 & 31.3 \\
Very dissatisfied (\%) & 5.6 & 5.0 & 4.3 & 2.6 \\
Leisure life satisfaction & & & & \\
Very satisfied (\%) & 6.3 & 4.4 & 4.6 & 5.0 \\
Slighty satisfied (\%) & 16.6 & 40.4 & 43.9 & 49.0 \\
Neutral (\%) & 42.5 & - & - & - \\
Slighty unsatisfied (\%) & 23.6 & 36.8 & 36.4 & 39.5 \\
Very dissatisfied (\%) & 11.0 & 18.4 & 15.1 & 6.4 \\
\hline
\end{tabular}

인 응답 비율이 2011년 59.5\%에서 2017년 66.1\%로 증가하는 양상을 보였다. 여가활동에 대한 만족도 결과 역시 비슷한 양상 을 보였다(Table 10).

청각장애인의 경제 상태 중 주관적으로 인식하는 소속 계층에 대해서 알아본 결과(Table 11), 자신을 하층으로 인식하는 비율 이 중상층으로 인식하는 비율보다 평균 1.5 1.9배 정도 더 높은 것으로 나타났지만, 연도별로는 2008년도 65.4\%에서 2017년 $59.9 \%$ 로 점차 감소하는 양상을 보였다.

\section{DISCUSSIONS}

본 연구에서는 2005년부터 최근까지 시행된 장애인실태조사 의 결과를 토대로 청각장애인의 현황 및 특성을 파악하여 청각 장애인의 재활복지서비스 정책 수립을 위한 기초자료로 활용하 고자 하였다. 이를 위해 전체 장애인의 현황을 분석하여 그 경향 을 파악한 후, 청각장애인의 일반적 특성, 청각보조기기 및 의사 소통, 청각장애인 교육 및 복지서비스 등의 다양한 영역으로 나 누어 살펴보았다.

전체 장애인 현황을 분석한 결과, 전국 장애인 추정 수는 2005년에서 2014년까지 증가 추세를 보이다가 2017년 약간 감 소하는 추세를 보였으며, 지역사회 거주 재가 장애인도 비슷한 양상을 보였다. 반면 시설에 거주하고 있는 장애인의 경우 지속 적 증가 추세를 나타내었다. 이러한 경향은 장애인 부모와 당사 자의 노령화, 1 인 가구화 등의 사회적 변화로 인해 사회적 돌봄 이 필요한 장애인의 수가 증가하게 되어 시설에서 거주하고 있는 장애인 수의 증가에 영향을 미쳤을 것으로 생각한다. 거주시설 은 대부분 경직적인 운영으로 인해 개별 장애인의 서비스 욕구 에 적극적으로 대응하기가 어렵고, 지역사회와의 단절로 인한 인 권침해 문제 및 COVID-19와 같은 집단 감염에 취약한 한계점 이 있다. 이에 우리나라에서는 1960년대부터 추진되어 온 장애 인의 탈시설 및 자립 정책을 강조하는 장애인 정책의 시대적 패 러다임의 변화에 따라 장애인이 시설에서 벗어나 지역사회에 거 주하며 자립생활을 할 수 있도록 많은 정책적 지원을 제공해 왔 지만, 여전히 개선해야 할 부분이 많은 것이 사실이다. 이와 관 련하여 문재인 정부에서는 장애인 분야의 국정과제로 '탈 시설 등 지역사회 정착 환경 조성'을 포함시켰고, 보호가 필요한 장애

Table 11. The subjective economic class perception of the hearing impaired

\begin{tabular}{|c|c|c|c|c|c|c|c|c|c|c|}
\hline & \multicolumn{4}{|c|}{ Hearing impaired (\%) } & \multicolumn{6}{|c|}{ Total population $^{\dagger}(\%)$} \\
\hline & 2008 & 2011 & 2014 & 2017 & 2009 & 2011 & 2013 & 2015 & 2017 & 2019 \\
\hline Upper middle class & 34.6 & 37.4 & 34.7 & 40.1 & 57.6 & 54.7 & 59.3 & 55.4 & 60.3 & 60.9 \\
\hline Lower class & 65.4 & 62.6 & 65.3 & 59.9 & 42.4 & 45.3 & 40.7 & 44.6 & 39.7 & 39.1 \\
\hline
\end{tabular}

${ }^{\dagger}$ From Statistics Korea’s social survey results 
인에 대해 향후 20 년간 단계적으로 시설이 아닌 지역사회에서 자립생활을 지원해 나갈 수 있는 '탈시설 장애인 지역사회자립 지원 로드맵’ 정책을 발표한 바 있다(Ministry of Health and Welfare, 2021b).

전체 장애 등록률은 2005년도 77.7\%에서 2011년 93.8\%로 $16.1 \%$ 증가하였고, 이후부터는 계속해서 $90 \%$ 이상을 상회하고 있다. 이러한 증가의 원인으로 2009년 장애아동 재활치료 바우 처 사업 도입, 2010년 장애인연금 도입 등 핵심적인 장애인 복지 서비스라고 할 수 있는 제도들이 도입되어 장애인의 삶의 질을 제고하는 데 기여함으로써 장애인 등록률 향상에도 영향을 미 쳤을 것으로 생각할 수 있다. 장애 출현율의 경우는 2005년 4.59\%에서 2011년 5.61\%로 상승하였으나, 2014년부터는 지속 적인 감소 추세를 보이고 있다. 2011년도까지 전체 장애 출현율 이 상승한 근거로는 평균 수명 연장에 따른 인구 노령화로 노령 기 장애의 증가, 사회참여 확대를 통한 산업재해와 교통사고의 증가 및 장애 발생 위험요인 증가 등의 이유를 들 수 있다(Korea Institute for Health and Social Affairs, 2011). 하지만 이 러한 증가세는 2014년 장애인실태조사에서부터 점차 감소 추 세로 변화되고 있는데, 가장 큰 이유는 인구증가폭 대비 장애 인 증가율이 낮기 때문이다. 이는 의료기술의 발달로 질환이나 사고와 같은 장애의 후천적 원인 비율이 2008년과 2011년 각 각 $90 \%$ 와 90.5\%에서 2014년 88.9\%로 감소한 영향이 반영된 결과라고 분석하는 견해도 있다(Korea Institute for Health and Social Affairs, 2017). 최근 장애 출현율과 관련하여 산 출방식에 대한 다양한 변화 필요성이 제기되고 있다(Korean Disabled People's Development Institute, 2019). 이러한 배 경에는 장애 개념이 개인적 손상 이외에 '사회·환경적 맥락'을 강 조하는 국제기능장애건강분류(International Classification of Functioning, Disability and Health, ICF)의 개념으로 변 하고 있기 때문이다. 즉 우리나라의 경우 장애 출현율을 개인의 '손상'을 중심으로 15 개 장애유형으로 분류하여 산출하기 때문 에 장애 환경을 충분히 반영한 것으로 보기 어렵고, '손상'으로 인한 장애 이외에 사회적 편견이나 제도의 미비로 인하여 이동 및 활동제약 등의 장애는 제도권 내 포함되지 않고 있다. 그러므 로 우리나라에서도 국제적 장애 개념의 전환이라는 이슈에 부합 하기 위해서 '장애 출현율 산출도구'에 대한 변화의 필요성이 제 기되고 있는 것이다. 같은 맥락으로 Korean Disabled People's Development Institute(2019)에서 국제기능장애건강분류 (ICF) 장애 개념을 반영한 장애 출현율 산출도구를 활용하여 우 리나라의 장애 출현율을 조사한 결과, 연구 대상자의 $18.7 \%$ 가 '일상생활 및 사회참여에 제약이 있는 자'들로 조사되어 2017년 장애인실태조사의 장애 출현율인 $5.39 \%$ 와 상당한 차이가 있는 것으로 나타났다. 향후 이러한 결과를 토대로 '손상' 중심의 장
애 출현율 산출기준의 문제점을 재고하고, 개인의 손상 이외에도 사회·환경적 맥락을 강조한 국제기능장애건강분류(ICF)의 개념 을 도입해서 분석할 필요가 있을 것으로 생각한다.

청각장애인의 일반적 특성 중 청각장애의 출현율은 0.65 0.66\%로 지체장애, 뇌병변장애와 함께 높은 출현율을 보 였다. 최근 보건복지부가 발표한 '2020년도 등록장애인 현황'에 서 15 개 장애유형을 분석한 결과를 보면 지체장애가 $45.8 \%$ 로 가장 많았으며, 청각장애가 $15 \%$ 로 두 번째로 높은 비중을 나타 내어 장애 출현율뿐만 아니라, 전체 장애 중 청각장애가 차지하 는 비율이 상대적으로 높음을 알 수 있다(Ministry of Health and Welfare, 2020). 청각장애인의 연령분포는 만 65세 이상 에서 2008년 55.3\%, 2011년 57.2\%, 2014년 63.0\%, 2017년 $73.2 \%$ 로 높은 비율을 차지하여 노인성 난청인의 증가를 예측 할 수 있다. 청각장애는 관절염, 고혈압과 더불어 만성 질환의 유 병률이 높기 때문에 고령화 추세에 비추어 볼 때, 청각장애를 가 진 노인의 수는 지속적으로 증가할 것으로 예상되므로(Korea Institute for Health and Social Affairs, 2006; Korea Institute for Health and Social Affairs, 2009; Hwang et al., 2013) 다각적인 실태조사를 통해 노인성 난청인의 특성과 서 비스 욕구에 부합하는 적절한 복지서비스와 정책적 지원이 필요 하다.

청각장애 발생 원인은 선천적 요인보다 후천적 요인의 비율이 높아(2017년 기준 92.4\%) ‘후천적 장애 발생’ 예방교육 및 다양 한 대책이 필요하다. 특히 돌 이후에 청각장애가 발생하였다고 응답한 경우를 연령대별로 구분해서 살펴본 결과, 50 대 이후 청 각장애 발생률이 매년 50\% 이상으로 점차 증가하는 추세이므로 이 연령대에 대한 장애 발생의 예방 및 관리 대책의 마련이 중요 해지고 있음을 알 수 있다. 또한 청각장애인을 장애정도에 따라 구분해 보면, 중증 장애인은 2008년 43.4\%에서 2017년 33,2\% 로 감소하는 반면에 경증 장애인은 2008년 56.7\%에서 2017년 $66.8 \%$ 로 점차 증가하고 있다. 이에 개인의 욕구와 환경을 고려 한 맞춤형 서비스를 제공할 수 있는 장애인 복지 전달체계를 강 화할 필요가 있다.

청각보조기기와 의사소통 방법에 대한 분석 결과, 보청기를 사용하고 있는 청각장애인은 2008년 57.1\%에서 2017년 73.2\% 로 증가하고 있는 추세였으며, 보청기를 포함한 청각보조기기 구입경로는 '청각보조기기 업체 매장'에서 가장 많이 구입하고 있는 것으로 나타났다. 국내 보청기 시장 규모는 2014년 기준 약 616억 원이었으나(Korea Health Industry Development Institute, 2015), 최근 중고도 이상의 난청자를 대상으로 지원 되는 정부 보청기 지원금이 2013년 42억 원에서 2017년 645억 원으로 15 배 증가한 것을 감안할 때, 엄청난 속도로 성장하고 있 고 이러한 추세는 향후 지속될 것으로 예상된다. 특히, 인구의 고 
령화에 따른 노인성 난청인구의 증가와 보청기 지원금 확대로 보 청기에 대한 공공성 확보 및 보청기 전문가의 서비스 질과 관련 된 제도 개선과 인식의 필요성이 제기되었다. 이와 관련하여 Bae and Hwang(2018)은 보청기 전문가의 서비스 질 향상이 보청기 착용에 대한 만족도 개선으로 연계되고, 반품률 감소와 보청기 급여와 관련된 국민세금의 효과적 사용에 긍정적인 영향을 미치 는 것으로 보고하여 합리적인 보청기 지원 정책과 청각 전문가에 의한 보청기 적합 및 재활서비스 제공의 확대와 개선이 필요함을 시사하고 있다.

청각장애인의 보조기기 사용 만족도는 '만족스럽다’고 응답한 비율이 2008년 51.9\%에서 2017년 69.4\%로 17.5\% 상승하였으 며, 청각장애인은 주된 의사소통 방법으로 '말'을 사용한다는 비 율이 평균 $80 \%$ 가 넘었고, 그 다음이 수화, 구화(입모양), 필담의 순으로 나타났다.

청각장애인의 교육과 관련하여 '학교에 다니지 않는 비율'을 학교 형태별로 분석한 결과, 초등학교에서 고등학교로 올라갈수 록 그 비율이 증가하여 교육의 정도가 낮아짐을 알 수 있었고, 다른 주요 장애 영역과 비교한 결과 청각장애인이 학교에 다니지 않는 비율이 가장 높게 나타났다. 본 연구에서는 청각장애인의 교육과 관련하여 단편적인 부분만을 분석하였지만, 청각장애인 의 전반적인 교육수준의 향상이 필요함을 알 수 있었고, 이를 위 한 정부의 재정적인 지원 강화가 필요할 것으로 생각된다. 이와 함께 최근 인공와우 수술과 재활이 확대되면서 청각장애 특수 학교의 학생 비율이 감소하고, 일반학교로 통합되는 비율이 증 가하는 등 청각장애교육 환경에 많은 변화가 발생하고 있으므로 이에 대한 다양한 대책이 필요하다. 특히 미국이나 호주의 학교 기반(school-based audiology service) 재활서비스 제공 인력 양성 및 서비스 체계화 방안을 도입하여 재활 전문가의 중재(바 우처 서비스)를 통한 청각장애교육을 보완하고, 그 변화에 대응 해 나갈 수 있도록 하는 방안에도 많은 관심과 노력이 필요하다 (Koo et al., 2015).

청각장애인으로 등록한 후 받은 혜택에 대해 '별로 받지 못하 고 있다'와 '전혀 받지 못하고 있다'로 부정적인 응답을 한 비율이 2008년 58.5\%, 2011년 64.4\%, 2017년 64.1\%로 점차 증가하 는 양상을 보였다. 또한 청각장애인의 복지욕구는 2008년의 경 우 의료보장 요구(33.8\%), 소득보장 요구(21.7)가 높게 나타났고 2011년부터는 이 항목의 순서가 바뀌어서 2017년의 경우 소득 보장 요구가 $40.4 \%$ 로 높게 나타났다.

청각장애인의 생활만족도를 살펴보면, '현재 삶에 만족한다'는 긍정적인 응답 비율이 2011년 59.5\%에서 2017년 66.1\%로 증 가하는 양상을 보였지만, 전체 장애 영역과 비교해 볼 때 평균보 다 약간 높게 나타난 정도이다(Koo et al., 2015). 반면 2008년 에는 '삶에 대해 만족한다'는 비율이 $26.4 \%$ 에 불과했는데, 이
는 설문조사 척도의 차이로 인한 결과라고 해석할 수 있다(Han \& Kum, 2017). 청각장애인의 생활만족도와 관련한 Kim and Lee(2013)의 연구 결과에 의하면, 청각장애인은 경제활동에 참 여할수록 생활만족도가 높은 것으로 나타났다. 즉 청각장애는 고유한 언어체계와 그에 따른 독특한 인지발달 및 강한 농문화 에 대한 결집력 등으로 인하여 전문적인 직업재활 개입이 요구되 는 장애유형으로 청각장애인이 원하고 잘 할 수 있는 분야의 직 업을 갖는다면, 이직률을 줄이고 생활만족도를 높일 수 있으므 로 이에 대한 다양한 대책도 고려되어야 할 것이다.

청각장애인의 경제 상태에 대한 인식 조사에서 자신을 하 층으로 인식하는 비율이 중상층으로 인식하는 비율보다 평균 1.5 1.9배 정도 더 높게 나타났고, 전체 인구와 비교했을 때도 많 은 차이를 보였다. 이와 관련하여 통계청에서 실시하는 전체 인 구 대상 '사회조사'에 의하면, 2019년 기준 전체 인구의 60.9\% 가 자신을 중상층으로 인식하는 것으로 나타나 청각장애인의 인 식과 많은 차이를 나타내었다. 또한 최근 조사에 의하면, 전체 장 애인의 $69.4 \%$ 는 자신의 가구를 경제적으로 어려운 저소득 가구 (일반 가구의 1.8 배)로 인식하는 것으로 조사되었다(Statistics Korea, 2019). 이러한 결과는 최근 COVID-19의 어려움이 일 상의 불편함을 넘어 소득 격차로까지 이어져 청각장애인들의 삶 에 대한 어려움을 가중시켜 이들의 소득보장 요구가 더욱 증가할 것으로 예상되므로 다양한 경제적 지원책이 마련되어야 할 것이 다.

이상의 결과를 통해서 COVID-19와 같은 위기 상황 속에서 청각장애인에 대한 다양한 정책 및 지원서비스에 대한 요구가 더 욱 증가할 것을 예상할 수 있다. 향후 주기적으로 실시되고 있는 장애인실태조사 외에 청각장애의 다양한 특성을 반영한 종단적 인 연구를 확대한다면, 청각장애인을 위한 중·장기적인 복지정책 마련의 근거가 될 수 있을 것으로 기대한다.

중심 단어: 청각장애, 청각장애인, 장애인실태조사, 재활복지 서비스.

\section{Ethical Statement}

N/A

\section{Acknowledgments}

N/A

\section{Declaration of Conflicting Interests}

There is no conflict of interests. 


\section{Funding}

N/A

\section{Author Contributions}

Conceptualization: Soo Jin Cho, Mi Sook Lee, Yu Ri Lee.

Data curation: Soo Jin Cho. Formal analysis: All authors. Investigation: All authors. Methodology: All authors. Writingoriginal draft: Soo Jin Cho, Mi Sook Lee. Writing-review \& editing: Yu Ri Lee. Approval of final manuscript: All authors.

\section{ORCIDiD}

Soo Jin Cho

https://orcid.org/0000-0003-1752-5172

Mi Sook Lee https://orcid.org/0000-0003-4065-9849

Yu Ri Lee https://orcid.org/0000-0002-4860-7325

\section{REFERENCES}

Bae, S. Y. \& Hwang, M. J. (2018). Trends and implications of complaints related to hearing aids by elderly consumers. Consumer Policy Trends, 94, 1-22.

Han, H. \& Kum, H. (2017). An empirical study on comparability of satisfaction measurement tools: focusing on 4, 5 and 11 likert type items for public service satisfaction survey. Survey Research, 18(1), 61-96.

Hwang, J., Shin, E. Y., \& Kim, J. (2013). A study on hearing self-status and aural rehabilitation program needs of the elderly who attend geriatric welfare. Audiology, 9(2), 175-189.

Kim, J. S. \& Lee, S. Y. (2013). The effects of social support on life satisfaction of deaf pepole: the perspective of economic assistance and needs-based assistance. Journal of Disability and Welfare, 22, 25-46.

Koo, S. M., Cha, O. S., \& Lee, S. M. (2015). The 18th Academic
Conference of Korea Academy Audiology: A Summary of the Census for the Disabled In Korea: Focusing on the Hearing Impaired Person-Update. Chuncheon, Gangwon: Korea Academy Audiology.

Koo, S. M., Kim, J. S., \& Lim, D. (2006). A summary of the census for the disabled in Korea-focusing on the hearing impaired. Audiology, 2(1), 52-57.

Korea Health Industry Development Institute. (2015). Market analysis of medical device major items: hearing aids. KhiDI Brief, 34, 1-8.

Korea Institute for Health and Social Affairs. (2006). 2005 Survey on the Disabled. (pp.1-534). Sejong: Ministry of Health and Welfare.

Korea Institute for Health and Social Affairs. (2009). 2008 Survey on the Disabled. (pp.1-534). Sejong: Ministry of Health and Welfare.

Korea Institute for Health and Social Affairs. (2011). 2011 Survey on the Disabled. (pp.1-672). Sejong: Ministry of Health and Welfare.

Korea Institute for Health and Social Affairs. (2017). 2017 Survey on the Disabled. (pp.1-726). Sejong: Ministry of Health and Welfare.

Korean Disabled People's Development Institute. (2019). A Study on the Reorganization Plan for the Prevalence of Disability in Korea: Based on the ICF Disability Concept. Seoul: Korean Disabled People's Development Institute.

Ministry of Health and Welfare. (2020). 2020 Disabled Registration Status. Ministry of Health and Welfare. Retrieved from https:// www.mohw.go.kr/react/jb/sjb030301ls.jsp?PAR_MENU_ ID $=03 \& M E N U \_I D=0321 \& S E A R C H K E Y=T I T L E \& S E A R C H V A$ LUE=\%EC\%9E\%A5\%EC\%95\%A0\%EC\%9D\%B8\#.

Ministry of Health and Welfare. (2021a, April 20). 2020 Survey on the Disabled. Ministry of Health and Welfare. Retrieved from http://www.mohw.go.kr/react/al/sal0301vw.jsp?PAR_MENU_ ID=04\&MENU_ID=0403\&CONT_SEQ=365357\&page=1.

Ministry of Health and Welfare. (2021b, August 2). Roadmap for Supporting Self-Reliance in the Community for Deinstitutionalization Disabled People. Ministry of Health and Welfare. Retrieved from http://www.mohw.go.kr/react/al/sal0301vw.jsp?PAR_MENU_ $\mathrm{ID}=04 \& M E N U \_I D=0403 \&$ page $=1 \& C O N T \_S E Q=366703$.

Statistics Korea. (2019, November 25). 2019 Social Survey Results. Statistics Korea. Retrieved from https://kostat.go.kr/portal/korea/ kor_nw/1/6/3/index.board. 